This document is the accepted manuscript version of the following article:

Manasfi, T., De Méo, M., Coulomb, B., Di Giorgio, C., Ravier, S., \& Boudenne, J. L. (2019). Development of transient mutagenic activity following the chlorination of the sunscreen UV filter dioxybenzone (benzophenone-8) in bromide-rich water. International Journal of Hygiene and Environmental Health, 222(4), 663-669. https://doi.org/10.1016/j.ijheh.2019.04.003

\title{
Development of transient mutagenic activity following the chlorination of the sunscreen UV filter dioxybenzone (benzophenone-8) in bromide-rich water
}

Tarek Manasfi a,b*, Michel De Méoc ${ }^{c}$, Bruno Coulomba ${ }^{a}$, Carole Di Giorgioc ${ }^{c}$ Sylvain Ravier ${ }^{a}$, Jean-Luc Boudenne $^{\mathrm{a}}$

a Aix-Marseille Université, CNRS, LCE UMR 7376, 13331 Marseille, France

${ }^{\mathrm{b}}$ current address: Eawag, Swiss Federal Institute of Aquatic Science and Technology, 8600

Dübendorf, Switzerland

c Aix Marseille Université, CNRS, IRD, Avignon Université, IMBE UMR 7263, Laboratoire de Mutagénèse Environnementale, 13385, Marseille, France

\section{Keywords:}

Sunscreen organic UV filters, chlorination, disinfection byproducts, mutagenicity, halogenated transformation products

\begin{abstract}
The mutagenicity of four organic UV filters namely oxybenzone (benzophenone-3), dioxybenzone (benzophenone-8), avobenzone, and octyl methoxycinnamate, in chlorinated bromide-rich water (artificial seawater) was investigated. Mutagenicity was evaluated using Ames test in Salmonella typhimurium TA98 without S9 mix. Chemical analysis using highresolution mass spectrometry was carried out to elucidate the mutagenic transformation products. Among the studied UV filters, only dioxybenzone exhibited a clear mutagenic activity following chlorination in seawater at ratio 1:10 (UV filter:chlorine). In contrast, no mutagenic activity was detected when chlorine was added at higher doses (ratio 1:1000). High-resolution mass spectrometry analysis showed that mutagenic extracts contained several brominated transformation products of dioxybenzone. Time course analysis of the transformation products at increasing chlorine doses showed that they were unstable and disappeared more quickly at higher chlorine doses. This instability explained the absence of mutagenic activity of dioxybenzone when 1000-fold excess chlorine was added, as no transformation products were detected. Relevance of these findings to the context of swimming pool is discussed. Further investigations taking into consideration the mutagenicity of not only the intermediate transformation products but also the final disinfection byproducts are needed to determine the
\end{abstract}


overall impact of high levels of chlorine on the overall mutagenicity. This study highlights the importance of considering the reactivity of organic UV filters and their transformation products in disinfected recreational waters when sunscreen formulations are prepared.

\section{Introduction}

Protection against excessive exposure to ultraviolet (UV) light is recommended as one of the major preventive measures to reduce risks of skin cancer (American Cancer Society, 2016). Sunscreens are an adjunct to clothing and other physical means of solar UV radiation protection (CDC, 2018). In sunscreens, inorganic and/or organic UV filters are the active ingredients since these compounds act mainly by reflecting and scattering (inorganic) or absorbing (organic) radiation. In sunscreens, usually more than one UV filtering agents are added to achieve a broad-spectrum protection against UV radiation (Serpone et al., 2007). The concentrations of UV filters in the final sunscreen product should not exceed certain maximum concentrations, which vary from one country or region to another. In the US, the FDA published a final sunscreen monograph in the 1999, which included 16 sunscreen active ingredients including avobenzone, dioxybenzone (DIOXY or Benzophenone-8 (BP-8)), oxybenzone (benzophenone3 (BP-3)), octocrylene, and octylmethoxy cinnamate (OMC or octinoxate) (FDA, 1999). In the European Union, REGULATION (EC) No 1223/2009 on cosmetic products defines UV filters allowed in cosmetic products as well as the maximum concentrations in the final preparations (EC, 2009). Among the allowed UV filters in the EU are: oxybenzone, avobenzone, octocrylene, OMC, but not DIOXY. However, the latter has been detected in some swimming pool waters in Europe (Ekowati et al., 2016; Lempart et al., 2018). In addition to their interest for protecting consumers, UV filters are also added to some cosmetic products to confer protection for products against photodegradation. Although the benefits of use of sunscreens is well established in helping to protect against sunburns, skin ageing, and skin cancer, there are some concerns about adverse effects of some UV filtering agents. Among the adverse effects or risks of some UV filters: trolamine salicylate risks include the potential for bleeding and increased salicylate toxicity (FDA, 2019), and para-aminobenzoic acid (PABA) risks include allergic and photoallergic skin reactions (Fisher, 1992). Besides, the potential percutaneous absorption of some UV filters and the subsequent induction of systemic effects such as estrogenic and antiandrogenic activity has been one of the major concerns (Schlumpf et al., 2001; Ma et al., 2003; Krause et al., 2012). In addition, UV filters have been shown to affect the aquatic environment to which they can enter either indirectly in wastewater or directly from recreational activities such as swimming (Giokas et al, 2007). The described environmental effects include coral bleaching (Danovaro et al., 2008), effects on marine bacterioplankton 
(Danavaro and Corinaldesi, 2003), and endocrine disruption (Schreurs et al., 2004; klann et al., 2005; Brausch and Rand, 2011). Many UV filters possess high lipophilicity allowing them to bioaccumulate in aquatic organisms (Tsui et al., 2014). Another active area of research regarding UV filters is the study of their transformation in the environment or in recreational areas such as swimming pools when exposed to light or oxidants such as chlorine. There are growing concerns regarding the formation of potentially toxic transformation products or byproducts from UV filters (Li et al., 2016). Although UV filters are required to be photostable to fulfill their role in sunscreens, there have been some reports about the photodegradation of certain UV filters (such as OMC) and increased toxicity following phototransformation (DiazCruz et al., 2008). Furthermore, the reaction of UV filters with chlorine added for disinfection of swimming pool water or in wastewater treatment plants has received the attention of researchers since several years. In these studies, halogenated transformation products and disinfection byproducts (DBPs) have been identified for several organic UV filters (Santos et al., 2012; Duirk et al. 2013; Sakkas et al. 2003; Negreira et al. 2008; Manasfi et al., 2015; Trebše et al., 2016; Kalister et al., 2016; Manasfi et al., 2017a). Despite evidence of transformation and formation of DBPs, there have been very few studies investigating the toxicity of the formed transformation products. Liu et al (2014) investigated the transformation and toxicity of 14 benzophenone-type UV filters during chlorination. Toxicity was examined using the photobacterium bioassay method that quantifies the decrease in light emission in Photobacterium phosphoreum because of exposure. In this study, only the UV filter benzophenone-13 (BP-13) was found to induce significant increase of toxicity following chlorination. However, in another study by Li et al. (2016), enhanced toxicity was observed following the chlorination of several BP-type UV filters. Grbović et al. (2016) found that the chlorination byproducts of UV filter hexyl 2-(4-diethylamino-2-hydroxybenzoyl) benzoate (DHHB) induced toxic response in daphnids. Mutagenicity is an endpoint of concern with regard to the toxicity of halogenated transformation products of UV filters in swimming pool water. Nakajima et al. (2009) detected weak mutagenic activity using Ames test in Salmonella typhimurium strain TA100 without metabolic fraction S9 mix for the transformation products of OMC in aqueous solution treated with chlorine. Zhang et al. (2016) detected mutagenic activity using SOS/umu test after the chlorination of oxybenzone spiked into ultrapure water. However, despite these few studies, there is a major knowledge gap regarding the toxicity of the formed transformation products and in particular their mutagenic potential. To our knowledge, the mutagenicity of transformation products of UV filters in bromide-rich water (e.g. seawater and brackish water) has not been described so far. In this type of water, upon the 
addition of chlorine, bromine is formed as a product from the reaction between bromide and chlorine (Deborde and Von Gunten, 2008). Bromine reacts with organic compounds leading to the formation of brominated transformation products and brominated DBPs, known to be far more toxic than their chlorinated analogues (Richardson et al., 2007, Manasfi et al., 2017b). To better understand the mutagenicity of halogenated transformation products of UV filters, the mutagenicity of five commonly used UV filters treated with chlorine in seawater was investigated using the Ames test. When a mutagenic activity was detected, to corroborate the findings and understand their origin, chemical analysis using high-resolution mass spectrometry (HRMS) was performed to identify the transformation products responsible for mutagenic activity.

\section{Materials and Methods}

\section{Chemicals}

Ultrapure water was produced from a Millipore water system (resistivity > $18 \mathrm{M} \Omega . \mathrm{cm}$ ). Standards of the studied UV filters (purity $>98 \%$ ) were purchased from Sigma-Aldrich. Benzophenone-d10 (Sigma-Aldrich Fluka) was used as an internal standard. 2,4,6-tribromo-3methoxyphenol (TBMP) was purchased from Sigma-Aldrich (Saint-Quentin Fallavier, France). Salicylic acid (purity > 99\%) was purchased from Acros Organics (Geel, Belgium). Ammonium formate (UHPLC/MS grade) was purchased from Biosolve Chimie (Dieuze, France). Methyl tert-butyl ether (MTBE) Chromosolv, HPLC grade, was purchased from Sigma-Aldrich, Germany. Dimethyl sulfoxide (DMSO), Chromasolv plus, $\geq 99.7 \%$ was purchased from SigmaAldrich, UK.

Stock solutions of chlorine were prepared by diluting a reagent grade commercial solution of sodium hypochlorite ( $\mathrm{NaOCl}$, available chlorine 4.00-4.99\%, Sigma-Aldrich). Artificial seawater was prepared according to the ASTM International standard practice for the preparation of substitute ocean water (method D1141-98, 2013). Stock solutions of UV filters were prepared in methanol (LC-MS UltraChromasolv) and used to spike artificial seawater.

Dibrominated salicylic acid was produced by chlorinating salicylic acid in artificial seawater according to the same procedure followed for the UV filters (described in the following section).

For Ames test, the Salmonella typhimurium tester strain TA98 was used. This strain was generously supplied by Prof. B.N. Ames (Berkeley, CA, USA). The strain was stored at -80 ${ }^{\circ} \mathrm{C}$ and regularly checked for genetic markers. 


\section{Chlorination of UV filters in seawater}

Chlorination experiments of the UV filters were carried out at $25{ }^{\circ} \mathrm{C}$. Glass vials with PTFElined screw caps of $65 \mathrm{~mL}$ capacities were filled with artificial seawater and placed in a water bath adjusted to $25{ }^{\circ} \mathrm{C}$. Individual UV filters in stock solutions were used to spike artificial seawater at a concentration of $10 \mu \mathrm{M}$ into separate vials. Chlorine was then added (in the form of $\mathrm{NaOCl}$ solution) in a volume corresponding to the desired molar ratio of $1: 10,1: 100$, and 1:1000 (UV filter:chlorine). Chlorination reactions were then stopped at different time points by adding sodium thiosulfate as a quenching agent. Sodium thiosulfate was added in 10-fold excess (molar equivalents) with respect to chlorine concentrations. Accordingly, $0.158 \mathrm{~g}, 1.58$ $\mathrm{g}$, and $15.8 \mathrm{~g}$ were added to quench reactions at chlorination ratios 1:10, 1:100, and 1:1000, respectively. Sample aliquots $(50 \mathrm{~mL})$ were then collected and extracted using liquid-liquid extraction (LLE) with MTBE (5 mL). Organic extracts $(4 \mathrm{~mL})$ were then separated from the aqueous phase and divided into two parts. One part $(1 \mathrm{~mL})$ was used to perform the chemical analysis using liquid chromatography coupled to high-resolution mass spectrometry (LCHRMS). The other part ( $3 \mathrm{~mL}$ ), for samples that were tested in Ames test, was treated as described in the following paragraph and used for mutagenicity testing in Salmonella typhimurium. To prepare samples for Ames test, the organic extracts $(3 \mathrm{~mL})$ were evaporated by placing the container vials in a water bath at $45^{\circ} \mathrm{C}$ and applying a stream of nitrogen gas. After evaporation, DMSO (0.5 mL) was added for solvent exchange. During solvent exchange, volatile and semi-volatile DBPs (such as bromoform, dibromoacetonitrile) are eliminated, which allows to directly correlate the results of Ames test with the identified non-volatile transformation products of the UV filters. These transformation products are more specific to the UV filters in comparison to the formed DBPs (such as bromoform) which can be produced by diverse precursors including multiple UV filters as described previously by Manasfi et al. (2017).

The same sample treatment was applied to prepare extracts from seawater spiked with UV filters without treatment with chlorine, in order to examine the mutagenicity of the starting products and to ensure that the extraction procedure did not engender any products that could contribute to mutagenicity.

The use of artificial seawater in these experiments was a critical element in the present study, as this ensured that the only organic compound present in solution was the spiked UV filter. As such, any identified transformation product and observed mutagenicity could be linked to the spiked UV filter without any interference from other organic precursors. This is unlike in 
natural seawater, where natural organic matter and possibly other present contaminants could also react with the added chlorine contributing to the formation of transformation products and DBPs.

\section{Salmonella mutagenicity assay (Ames test)}

The mutagenicity assay was carried out according to Maron and Ames (1983), with a modified version of the liquid-incubation technique as described previously (De Méo et al., 1996). The Salmonella tester strain TA98 was used for this study since this strain is capable of detecting frameshift mutations which are more likely to be caused by voluminous compounds (such as polycyclic compounds) (Isono and Yourno, 1974; Maron and Ames, 1983). Bacteria were grown for $12 \mathrm{~h}$ at $37{ }^{\circ} \mathrm{C}$ in Oxoid Nutrient Broth $\mathrm{N}^{\circ} 2$ containing ampicillin ( $\left.25 \mu \mathrm{g} / \mathrm{mL}\right)$ with gentle shaking. After the incubation period, various volumes of extracts of UV filters were added to $0.1 \mathrm{~mL}$ of the overnight culture and $0.1 \mathrm{~mL}$ of PBS, to test four different sample concentrations. The obtained mixtures were incubated for $60 \mathrm{~min}$ in the dark. Melted top agar ( $2 \mathrm{~mL}$ ) containing $0.045 \mathrm{mM}$ histidine and biotin was then added. The final mixtures were then poured onto Vogel-Bonner (VB) minimal plates. For each series of experiments, negative controls with DMSO $(10 \mu \mathrm{L})$ were included to determine the number of spontaneous revertants/plate. 2,4,7-trinitrofluorenone (TNF) was used as a positive control. After incubation for $48 \mathrm{~h}$, revertant bacterial colonies were counted using an automatic counter (Scan 1200, Interscience, Saint Nom La Bretèche, France). Raw results of Ames test were expressed as number of revertants per plate (rev/plate).

Taking into consideration the relevance of our study to swimming pool water where UV filters are introduced by swimmers to disinfected waters, we did not use S9 mix. Previous investigations showed that disinfected drinking and swimming pool waters were most mutagenic in the absence of S9 mix (Takanashi et al. 2009; Nakajima et al., 2008; Richardson et al., 2010; Manasfi et al., 2016).

For the interpretation of results of Ames test, analysis was performed in two steps. First, the Dunnett test was carried out to determine if there was a significant difference between the mean number of induced revertants in exposed plates as compared to the mean number of spontaneous revertants in the negative control plates (Kim and Margolin, 1999). If the Dunnett test was positive for at least one dose, a nonlinear regression analysis was performed using an arbitrary model with TableCurve 2D software (version 5.01, Jandel Scientific Software, San Rafael, CA), as described by Kim and Margolin (1999). The used model was based on the following equation: 
Rev $/$ plate $=(a+b \times D) \times 2^{-c \times D^{2}}$

where Rev/plate is the number of revertants by plate, $\mathrm{D}$ is the dose, and a, b, and c are calculated coefficients.

Model significance validation was evaluated based on two criteria: (i) model probability $(P)$ being $<0.05$ and (ii) error probability $\left(P_{\mathrm{E}}\right)$ being $>0.05$. The mutagenic activity (MA, rev/ $\left.\mu \mathrm{g}\right)$ was defined as the maximal slope of the ascending part of the dose-response curve and was calculated as the first derivative at the origin.

\section{Analytical methods}

UPLC-HRMS Analysis. Extracts of field and laboratory samples were analyzed using UPLC system (Acquity, Waters) coupled to quadrupole/time-of-flight mass spectrometry (Q/ToF-MS) with electrospray ion (ESI) source (Synapt G2 HDMS, Waters, MA, USA). Calibration curves were established for each UV filter by external standard approach using the reference standard. Benzophenone-d10 was used as surrogate. Calibration standards were prepared by spiking artificial seawater with UV filters and then performing the same procedure as for samples (LLEUHPLC-MS/MS).

Separations were carried out on a CORTECS UPLC C18 column $(2.1 \times 100 \mathrm{~mm}, 1.6 \mu \mathrm{m}$, Waters) at $40{ }^{\circ} \mathrm{C}$. The mobile phase consisted of A: Water with $5 \mathrm{mM}$ ammonium formate (Biosolve, 98\%) and B: Methanol (Optima LC-MS, Fischer) with 5 mM ammonium formate. Elution was carried out at a flow rate of $0.4 \mathrm{~mL} / \mathrm{min}$ with a gradient starting at $15 \%$ of solvent B and increasing to reach $100 \%$ of solvent B within 6 min and held for 1 min. The sample injection volume was $5 \mu \mathrm{L}$.

A solution of sodium formate (HCOONa, Waters Q-ToF product) was infused daily in the ESI source to calibrate the instrument. Optimum ESI conditions were found using a $2.5 \mathrm{kV}$ capillary voltage, $30 \mathrm{~V}$ sample cone voltage, $450{ }^{\circ} \mathrm{C}$ desolvation temperature, $120^{\circ} \mathrm{C}$ source temperature, $20 \mathrm{~L} / \mathrm{h}$ cone gas flow rate and $800 \mathrm{~L} / \mathrm{h}$ desolvation gas flow rate. The optimum sample cone voltage for each UV filter has been described previously (Manasfi et al., 2017a).

Identification of transformation products was based on accurate mass measurement (with mass error less than 5 ppm) and MSMS data. For transformation products available commercially in standard form (the case of TBMP), tentative identification was confirmed by comparing retention time and mass spectral data with those of the standard product. For dibrominated 
salicylic acid, identification was based on accurate mass measurement, MSMS spectral data, as well as comparison to chromatographic and spectral data of 3,5-dibromosalicylic acid.

\section{Results and Discussion}

\section{Mutagenicity of UV filters in chlorinated seawater}

The mutagenicity of the UV filters (non chlorinated and chlorinated in seawater at ratio 1:10 and 1:1000, reaction time $30 \mathrm{~min}$ ) was studied in Salmonella typhimurium strain TA98 without S9 mix.

Table 1 presents the raw results of Ames test for the DMSO extracts of the four tested UV filters in seawater without chlorination (Samples 1 to 4), with chlorination at UV filter:chlorine ratio 1:100 (Samples 5 to 8), and at ratio 1:1000 (Samples 9 to 12). For each sample extract, the mean reversion $(n=3)$ and standard deviation are presented for each of the four tested doses of each extract. As shown in Table 1, no increased reversion was detected for the non-chlorinated UV filters in comparison to the negative controls. Also, for the chlorinated UV filters, except for DIOXY at chlorination ratio 1:10 (UV filter:chlorine), no increased reversion was detected since reversion levels were similar to negative controls ranging 15 and $29 \mathrm{rev} / \mathrm{plate}$, indicating absence of mutagenic activity. However, for extracts of DIOXY chlorinated in seawater at ratio 1:10, a clear statistically significant mutagenic activity was detected with levels of reversion ranging from 61 to $158 \mathrm{rev/plate.} \mathrm{The} \mathrm{mutagenic} \mathrm{effect} \mathrm{increased} \mathrm{as} \mathrm{a} \mathrm{function} \mathrm{of} \mathrm{doses}(4,6,8$ and $10 \mu \mathrm{L}$ of the tested extract). An effect-dose relationship for the mutagenic activity of DIOXY at ratio 1:10, reaction time $0.5 \mathrm{~h}$ was established (Figure 1). The calculated coefficients of the selected model were: $\mathrm{a}=19.9$; $\mathrm{b}=7.1$ and $\mathrm{c}=-0.01$ giving $P<10^{-5}, P_{E}=0.06$. The mutagenic activity (MA, rev/ $\mu$ g), defined as the maximal slope of the ascending part of the dose-response curve and calculated as the first derivative at the origin, was $18.7 \mathrm{rev} / \mu \mathrm{L}$. 
Table 1. Raw reversion results of Ames test in Salmonella typhimurium TA98 without S9

\begin{tabular}{|c|c|c|c|c|}
\hline Sample Number & Sample Type & Dose & Mean (rev/plate), $n=3$ & Standard Deviation \\
\hline C1 & DMSO & $10 \mu \mathrm{l}$ & 20 & 5 \\
\hline TNF1 & TNF & $0.02 \mu \mathrm{g}$ & 352 & 16 \\
\hline $1-4$ & OXY & $4 \mu \mathrm{l}$ & 24 & 8 \\
\hline $1-6$ & OXY & $6 \mu l$ & 21 & 4 \\
\hline $1-8$ & $\mathrm{OXY}$ & $8 \mu \mathrm{l}$ & 24 & 3 \\
\hline $1-10$ & OXY & $10 \mu \mathrm{l}$ & 19 & 3 \\
\hline $2-4$ & DIOXY & $4 \mu \mathrm{l}$ & 26 & 7 \\
\hline $2-6$ & DIOXY & $6 \mu l$ & 19 & 5 \\
\hline $2-8$ & DIOXY & $8 \mu \mathrm{l}$ & 20 & 2 \\
\hline $2-10$ & DIOXY & $10 \mu \mathrm{l}$ & 21 & 2 \\
\hline $3-4$ & AVO & $4 \mu \mathrm{l}$ & 26 & 7 \\
\hline $3-6$ & AVO & $6 \mu l$ & 18 & 3 \\
\hline $3-8$ & AVO & $8 \mu \mathrm{l}$ & 23 & 3 \\
\hline $3-10$ & AVO & $10 \mu \mathrm{l}$ & 23 & 2 \\
\hline $\mathrm{C} 2$ & DMSO & $10 \mu \mathrm{l}$ & 19 & 2 \\
\hline TNF2 & TNF & $0.02 \mu \mathrm{g}$ & 351 & 3 \\
\hline $4-4$ & OMC & $4 \mu \mathrm{l}$ & 24 & 7 \\
\hline $4-6$ & OMC & $6 \mu \mathrm{l}$ & 27 & 1 \\
\hline $4-8$ & OMC & $8 \mu \mathrm{l}$ & 24 & 1 \\
\hline $4-10$ & OMC & $10 \mu \mathrm{l}$ & 23 & 2 \\
\hline 5-4 & OXY R 1:10 & $4 \mu \mathrm{l}$ & 29 & 6 \\
\hline $5-6$ & OXY R 1:10 & $6 \mu \mathrm{l}$ & 22 & 3 \\
\hline $5-8$ & OXY R 1:10 & $8 \mu l$ & 18 & 7 \\
\hline $5-10$ & OXY R 1:10 & $10 \mu \mathrm{l}$ & 24 & 6 \\
\hline $6-4$ & DIOXY R 1:10 & $4 \mu \mathrm{l}$ & 61 & 11 \\
\hline $6-6$ & DIOXY R 1:10 & $6 \mu \mathrm{l}$ & 74 & 6 \\
\hline $6-8$ & DIOXY R 1:10 & $8 \mu \mathrm{l}$ & 134 & 5 \\
\hline $6-10$ & DIOXY R 1:10 & $10 \mu \mathrm{l}$ & 158 & 8 \\
\hline $\mathrm{C} 3$ & DMSO & $10 \mu \mathrm{l}$ & 24 & 5 \\
\hline TNF3 & TNF & $0.02 \mu \mathrm{g}$ & 389 & 21 \\
\hline $7-4$ & AVO R 1:10 & $4 \mu \mathrm{l}$ & 18 & 1 \\
\hline $7-6$ & AVO R 1:10 & $6 \mu \mathrm{l}$ & 18 & 2 \\
\hline $7-8$ & AVO R 1:10 & $8 \mu \mathrm{l}$ & 15 & 2 \\
\hline $7-10$ & AVO R 1:10 & $10 \mu \mathrm{l}$ & 23 & 5 \\
\hline $8-4$ & OMC R 1:10 & $4 \mu \mathrm{l}$ & 21 & 2 \\
\hline $8-6$ & OMC R 1:10 & $6 \mu l$ & 17 & 2 \\
\hline $8-8$ & OMC R 1:10 & $8 \mu \mathrm{l}$ & 19 & 8 \\
\hline $8-10$ & OMC R 1:10 & $10 \mu \mathrm{l}$ & 21 & 4 \\
\hline $9-4$ & OXY R 1:1000 & $4 \mu \mathrm{l}$ & 22 & 3 \\
\hline $9-6$ & OXY R 1:1000 & $6 \mu \mathrm{l}$ & 21 & 4 \\
\hline $9-8$ & OXY R 1:1000 & $8 \mu \mathrm{l}$ & 23 & 3 \\
\hline $9-10$ & OXY R 1:1000 & $10 \mu \mathrm{l}$ & 19 & 4 \\
\hline $\mathrm{C4}$ & DMSO & $10 \mu \mathrm{l}$ & 22 & 3 \\
\hline TNF4 & TNF & $0.02 \mu \mathrm{g}$ & 376 & 18 \\
\hline $10-4$ & DIOXY R 1:1000 & $4 \mu l$ & 19 & 3 \\
\hline $10-6$ & DIOXY R 1:1000 & $6 \mu \mathrm{l}$ & 22 & 5 \\
\hline $10-8$ & DIOXY R 1:1000 & $8 \mu \mathrm{l}$ & 18 & 3 \\
\hline $10-10$ & DIOXY R 1:1000 & $10 \mu \mathrm{l}$ & 24 & 4 \\
\hline $11-4$ & AVO R 1:1000 & $4 \mu l$ & 23 & 5 \\
\hline $11-6$ & AVO R 1:1000 & $6 \mu \mathrm{l}$ & 26 & 5 \\
\hline $11-8$ & AVO R 1:1000 & $8 \mu \mathrm{l}$ & 22 & 3 \\
\hline $11-10$ & AVO R 1:1000 & $10 \mu \mathrm{l}$ & 19 & 4 \\
\hline $12-4$ & OMC R 1:1000 & $4 \mu \mathrm{l}$ & 23 & 6 \\
\hline $12-6$ & OMC R 1:1000 & $6 \mu \mathrm{l}$ & 25 & 4 \\
\hline $12-8$ & OMC R 1:1000 & $8 \mu \mathrm{l}$ & 21 & 5 \\
\hline $12-10$ & OMC R 1:1000 & $10 \mu \mathrm{l}$ & 23 & 4 \\
\hline
\end{tabular}

C: Negative control, TNF: 2,4,7-trinitrofluorene (positive control). Samples 1 to 4 are UV filters without chlorination. Samples 5 to 8 are chlorinated UV filters at ratio 1:10, and 9 to 12 are chlorinated UV filters at ratio 1:1000. Chlorination reaction time $=30 \mathrm{~min}$. 


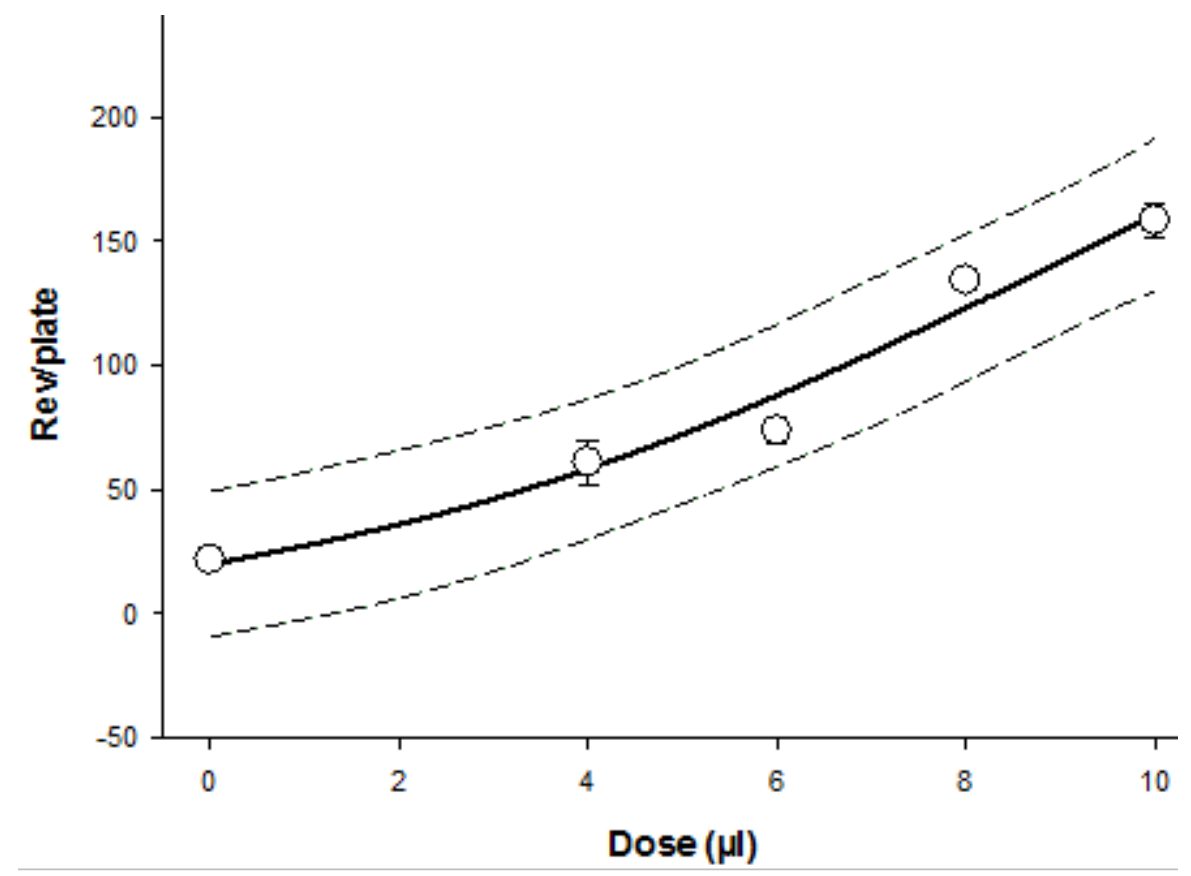

Figure 1. Dose-response relationship of DIOXY chlorinated in seawater at 1:10 (DIOXY:chlorine), reaction time $=30 \mathrm{~min}$, in Salmonella typhimurium strain TA 98 without $\mathrm{S9}$ mix.

White circles: revertant means \pm SD from triplicate plates; dashed lines: $99 \%$ confidence level.

To our knowledge, this is the first study to evaluate the mutagenicity of transformation products of UV filters following chlorination in artificial seawater. Previously, the mutagenicity of octyl dimethyl-p-aminobenzoate (ODPABA) and OMC following chlorination in buffered water was investigated (Nakajima et al., 2009). The chlorination intermediates of OMC exhibited weak mutagenic activity in Salmonella typhimurium TA100 strain without S9 mix. Mutagenicity decreased in the presence of S9 mix. Authors reported that the mutagenic activity disappeared within 7 hours following chlorination, suggesting the degradation of the mutagenic intermediate transformation products under the effects of chlorine.

In another study by Zhang et al. (2016), the genotoxicity of chlorination products of oxybenzone was studied using the SOS/umu genotoxicity test. Authors detected genotoxic activity following chlorination and ruled out the contribution of DBPs such as chloroform and haloacetic acids to the observed genotoxicity. In contrast, authors suggested a correlation between the concentrations of trichloromethoxyphenol and the observed genotoxicity.

The discrepancy between our findings and the findings of Zhang et al. (2016) regarding the genotoxicity of oxybenzone might be explained by the difference of employed genotoxicity assays, which detect genotoxic agents acting by different mechanisms. In the Ames test using Salmonella typhimurium TA98, frameshift mutations can be detected. However, the absence of effects using this test does not mean that the tested substance would not produce other types of 
toxicity in general and other mechanisms of genotoxicity in particular. This emphasizes the need of toxicological studies with different endpoints and different assays for the same endpoint to ensure that toxic effects are not overlooked.

\section{Transformation Products in chlorinated DIOXY sample presenting mutagenicity}

Extracts of chlorinated DIOXY in seawater were analyzed using UPLC-ESI-QToF-MS and MSMS to identify the transformation products that could be at the origin of the observed mutagenic activity. Analysis was performed in non-target screening and suspect screening modes. Suspect screening was performed based on previously identified transformation products of DIOXY (Manasfi et al., 2017a). In the mutagenic sample, five brominated transformation products namely Dioxy-Br, Dioxy-Br2, Dioxy-Br3, 3,5-dibromosalicylic acid, and TBMP were detected (Table 2). The formation of these brominated transformation products resulted from the reaction of bromine with DIOXY. In bromide-rich water, such as in seawater where bromide levels can reach $69 \mathrm{mg} / \mathrm{L}$, once chlorine is added to water it reacts with bromide ions leading to the formation of bromine, which reacts more rapidly with organic matter in comparison to chlorine (Deborde and Von Gunten, 2008).

The chlorination of organic UV filters has been shown to result in the production of compoundspecific transformation products as well as non-compound-specific DBPs such as chloroform and bromoform (Negreira et al., 2008; Duirk et al., 2013; Manasfi et al., 2015; Manasfi et al., 2017a). Some of the formed volatile and semi-volatile DBPs have been shown to be genotoxic (Richardson et al. 2008; Zhang el al., 2016; Manasfi et al. 2017b). However, in the present study, the preparation of extracts for Ames test involved the evaporation of the initial LLE solvent (MTBE) and solvent exchange with DMSO, which was compatible with the bioassay. This solvent exchange eliminated volatile and semi-volatile DBPs to narrow the mutagenic assessment to the non-volatile products. Therefore, the observed genotoxicity could be considered unrelated to volatile or semi-volatile DBPs, but rather a result of the formation of non-volatile transformation products. Besides, DBPs and specifically bromoform has been shown to be a common byproduct formed from all the UV filters studied here following chlorination in seawater (Manasfi et al. 2017a). However, since mutagenicity in chlorinated seawater was only detected in the case of DIOXY, this further suggests that the observed mutagenicity is not related to the common DBPs (ones formed by all the studied UV filters) but was rather related to intermediate non-volatile products specific to the UV filter in question. 
Table 2. Transformation products detected in mutagenic extract of DIOXY chlorinated in seawater

\begin{tabular}{|c|c|c|c|}
\hline $\begin{array}{l}\text { Detected } \\
\text { Transformation } \\
\text { Product }\end{array}$ & $\begin{array}{l}\text { Accurate Mass } \\
([\mathrm{M}-\mathrm{H}]-)\end{array}$ & $\begin{array}{l}\text { Chemical } \\
\text { Formula } \\
([\mathrm{M}-\mathrm{H}]-)\end{array}$ & Proposed Structure of the Molecule \\
\hline DIOXY-Br & $\begin{array}{l}320.9762 \\
322.9740\end{array}$ & $\mathrm{C} 14 \mathrm{H} 1004 \mathrm{Br}$ & $\stackrel{\mathrm{O}}{\mathrm{OH}}$ \\
\hline DIOXY-Br2 & $\begin{array}{l}398.8867 \\
400.8855 \\
402.8844\end{array}$ & $\mathrm{C} 14 \mathrm{H} 9 \mathrm{O} 4 \mathrm{Br} 2$ & \\
\hline DIOXY-Br3 & $\begin{array}{l}476.7973 \\
478.7952 \\
480.7932 \\
482.7911\end{array}$ & $\mathrm{C} 14 \mathrm{H} 8 \mathrm{O} 4 \mathrm{Br} 3$ & \\
\hline $\begin{array}{l}\text { Dibromosalicylic } \\
\text { Acid }\end{array}$ & $\begin{array}{l}292.8449 \\
294.8428 \\
296.8408\end{array}$ & $\mathrm{C} 7 \mathrm{H} 3 \mathrm{O} 3 \mathrm{Br} 2$ & \\
\hline TBMP & $\begin{array}{l}356.7762 \\
358.7740 \\
360.7721 \\
362.7701\end{array}$ & $\mathrm{C} 7 \mathrm{H} 4 \mathrm{O} 2 \mathrm{Br} 3$ & \\
\hline
\end{tabular}

All transformation products were detected in negative ESI mode

Zhang et al. (2016) investigated the genotoxicity of chlorination products of oxybenzone using the SOS/umu genotoxicity test. In this study, authors identified several chlorinated transformation products of oxybenzone as well as some DBPs including chloroform. However, 
when authors tested the genotoxicity of the formed DBPs separately (without the transformation products), no genotoxicity was detected, which allowed them to rule out the contribution of DBPs to the observed genotoxicity. Moreover, authors suggested a correlation between 2,4,6trichloro-3-methoxyphenol (chlorinated analogue of TBMP) and the observed genotoxicity. In our study, it was not possible to assign the observed mutagenicity to a specific transformation product. Further investigations are required to determine the transformation products directly responsible for the mutagenicity. Yet, some preliminary observation can be made by interpreting the mutagenicity results of the different UV filters on the light of previously identified transformation products. Along these lines, since TBMP is a common byproduct between DIOXY and OXY (Manasfi et al. 2017a), and no mutagenicity was detected for chlorinated OXY in seawater (conditions which form TBMP), it can be excluded from the candidate compounds responsible for the observed mutagenic activity of DIOXY chlorination products.

\section{Time course analysis of transformation products at different chlorination ratios}

Since DIOXY was the only UV filter shown to produce mutagenic activity in salmonella typhimurium strain TA98 upon chlorination in seawater, it was the subject of further chlorination experiments and analysis using HRMS to follow the kinetics of formation of the transformation products.

The kinetics of degradation of DIOXY and formation of its transformation products were followed as a function of reaction time at different UV filter:chlorine ratios $(1: 10,1: 100$ and l:1000). As shown in Figure 2, DIOXY disappeared rapidly in the presence of excess chlorine (precisely, in seawater the main oxidizing species is bromine) leading to the formation of brominated transformation products. The levels of the transformation products were highest at the lowest chlorination ratio (1:10). At chlorination ratio 1:100, all transformation products were still detected but at lower levels than those detected at ratio 1:10. At chlorination ratio 1:1000, most of the transformation products were not detected, except 3,5-dibromosalicylic acid which was detected at trace levels at $10 \mathrm{~min}$ but not anymore at $30 \mathrm{~min}$ (the extract tested in Ames test). The absence of the transformation products at ratio 1:1000 explains the absence of mutagenic activity in the same sample and further corroborates the correlation between mutagenicity and the identified transformation products.

These findings show that the formed transformation products are susceptible to react with bromine leading to their complete disappearance and the formation of bromoform and potentially other DBPs as final products (Manasfi et al., 2017a). The mechanism of cleavage of 
aromatic rings (e.g. phenols) when reacting with chlorine (and similarly bromine) and the subsequent formation of haloforms as final products has been described previously (Rook, 1974).
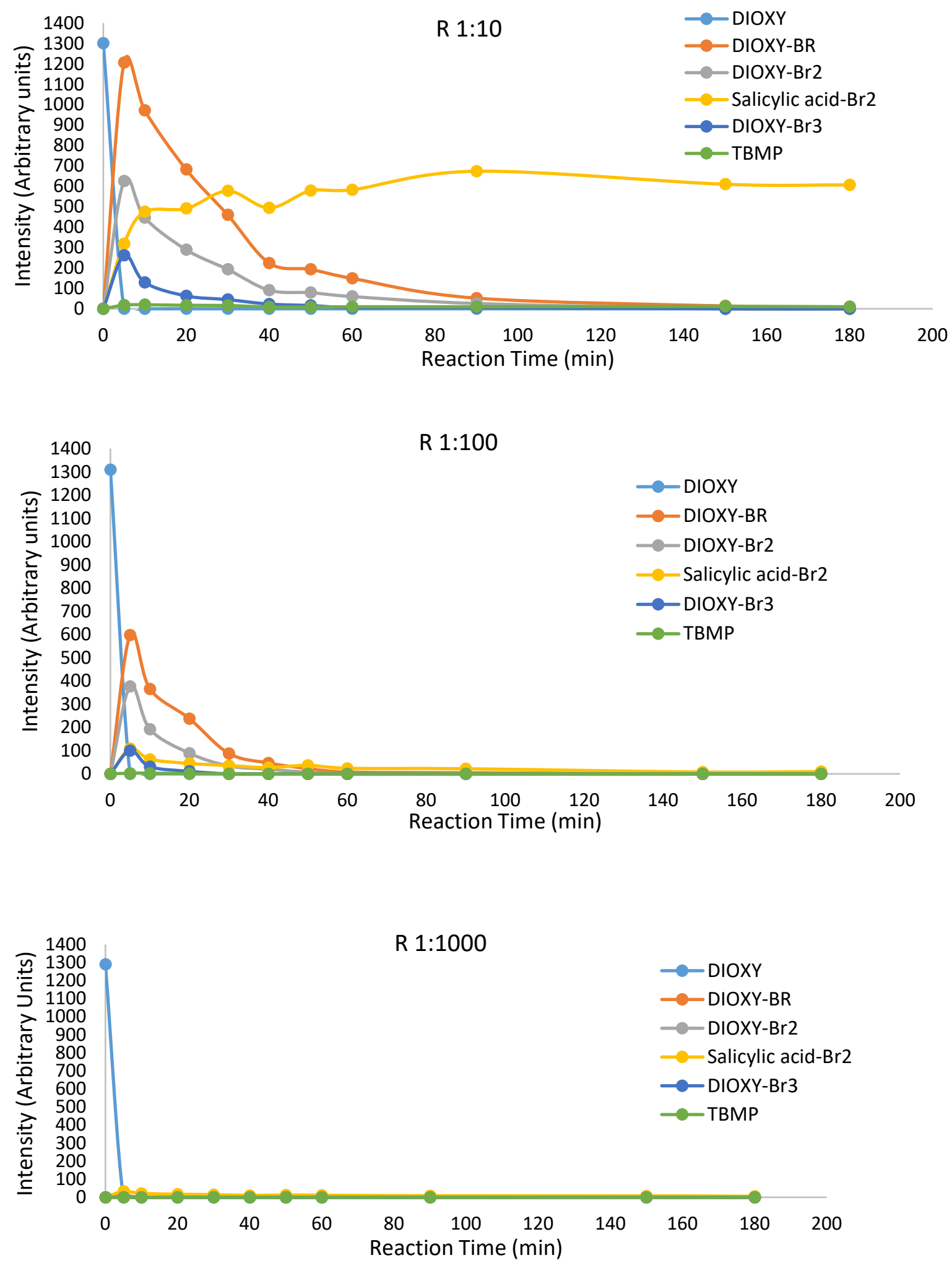

Figure 2. Time course of the decay of DIOXY and formation of transformation products in seawater at different UV filter:chlorine ratios (1:10, 1:100, and 1:1000) 


\section{Relevance of our findings to swimming pool context}

In real-world scenarios, recommended levels of free chlorine residual in swimming pools differ from one country to another and may vary from 0.3 to $3 \mathrm{mg} / \mathrm{L}$ (Ekowati etl al., 2016; Manasfi et al., 2017a). As to UV filters in general, concentrations ranging from sub ng/L up to few tens of $\mu \mathrm{g} / \mathrm{L}$ have been reported (Ekowati et al., 2016; Manasfi et al., 2017c). For DIOXY in particular, Ekowati et al. (2016) detected concentrations up to $21.6 \mathrm{ng} / \mathrm{L}$ in swimming pools in Spain. More recently, Lempart et al. (2018) reported levels up to $226.9 \mathrm{ng} / \mathrm{L}$ in swimming pools in Poland. Considering the molar mass of DIOXY (244.25 g/mol), the reported molar concentrations would be around 0.08 to $0.8 \mathrm{nmol} / \mathrm{L}$ (for 20 to $200 \mathrm{ng} / \mathrm{L}$ ). For a swimming pool containing $14 \mu \mathrm{mol} / \mathrm{L}$ (or $1 \mathrm{mg} / \mathrm{L}$ ) of free chlorine (expressed in the form of $\mathrm{Cl}_{2}$ ), this would mean a ratio ranging from 1:17500 to 1:175000 (DIOXY:chlorine) for the aforementioned DIOXY concentrations. As such, the transformation products detected in the present study at chlorination ratios lower than 1:1000 are likely to disappear rapidly in swimming pools where the UV filter:chlorine ratios are much higher. Nevertheless, investigations in real-case scenarios are still recommended since in swimming pool water, complex mixtures of organic matter (body fluids and personal care products released by swimmers, natural organic matter, etc.) compete for the reactions with chlorine, which may suggest that reactions in such matrices are recommended to rule out the occurrence of the transformation products in the pools.

\section{Conclusion}

The present study showed, for the first time to our knowledge, that the UV filter DIOXY could exhibit mutagenic activity when added to chlorinated bromide-rich water. In the mutagenic extracts, several brominated transformation products of DIOXY were detected. These transformation products were unstable, their levels decreased with increasing chlorine doses, and they were not detected at 1000-fold chlorine excess (1:1000, DIOXY:Chlorine). Although excess chlorine (or bromine in seawater) in this case resulted in the elimination of mutagenic activity by eliminating the mutagenic intermediate transformation products, excess chlorine is known to enhance the formation of DBPs, which were not tested in Ames test due to their elimination during solvent exchange of extracts. Some DBPs are known to be mutagenic (Richardson et al., 2007; Manasfi et al. 2017a). Therefore, future investigations taking into consideration both intermediate transformation products as well as DBPs are recommended to assess the effects of increasing chlorine doses on the overall mutagenicity (both DBPs and transformation products) in chlorinated/brominated samples. This study highlights the 
importance of taking into consideration the susceptibility of some UV filters to react with disinfectants in recreational waters when sunscreen formulations are designed.

\section{References}

American Cancer Society, “Melanoma Skin Cancer”' (available at https://www.cancer.org/cancer/melanoma-skin- cancer.html, accessed March 03, 2019.

Centers for Disease Control and Prevention (CDC), “'Skin Cancer: Sun Safety” (available at https://www.cdc.gov/cancer/skin/basic_info/ sun-safety.htm), accessed March 03, 2019.

Serpone, N., Dondi, D., \& Albini, A. (2007). Inorganic and organic UV filters: Their role and efficacy in sunscreens and suncare products. Inorganica Chimica Acta, 360(3), 794-802 FDA Sunscreen drug products for over-the-counter human use, Final Monograph, Federal Register 64 27666, US Food and Drug Administration, Rockville, MD, 2000. Available from: <http://www.cfsan.fda.gov/ /rd/fr990521.html>.

European Commission. (2009). Regulation (EC) No 1223/2009 of the European Parliament and of the Council of 30 November 2009 on cosmetic products. Off. J. Eur. Union, 50, 71-72.

Ekowati, Y., Buttiglieri, G., Ferrero, G., Valle-Sistac, J., Diaz-Cruz, M.S., Barceló, D., Petrovic, M., Villagrasa, M., Kennedy, M.D. \& Rodríguez-Roda, I. (2016). Occurrence of pharmaceuticals and UV filters in swimming pools and spas. Environmental Science and Pollution Research, 23(14), 14431-14441.

Lempart, A., Kudlek, E., Lempart, M., \& Dudziak, M. (2018). The presence of compounds from the personal care products group in swimming pool water. Journal of Ecological Engineering, 19(3).

Fisher, A.A., “'Sunscreen Dermatitis: Para-Aminobenzoic Acid and its Derivatives,'” Cutis, vol. 50(3), pp. 190- 192, 1992.

FDA Sunscreen Drug Products for Over-the- Counter Human Use, Proposed Rule, Federal Register/ Vol. 84, No. 38 / Tuesday, February 26, 2019 / Proposed Rules. 
Schlumpf, M., Cotton, B., Conscience, M., Haller, V., Steinmann, B., \& Lichtensteiger, W. (2001). In vitro and in vivo estrogenicity of UV screens. Environmental health perspectives, 109(3), 239-244.

Ma, R., Cotton, B., Lichtensteiger, W., \& Schlumpf, M. (2003). UV filters with antagonistic action at androgen receptors in the MDA-kb2 cell transcriptional-activation assay.

Toxicological Sciences, 74(1), 43-50.

Krause, M., Klit, A., Blomberg Jensen, M., Søeborg, T., Frederiksen, H., Schlumpf, M., ... \& Drzewiecki, K. T. (2012). Sunscreens: are they beneficial for health? An overview of endocrine disrupting properties of UV-filters. International journal of andrology, 35(3), 424436.

Giokas, D. L., Salvador, A., \& Chisvert, A. (2007). UV filters: from sunscreens to human body and the environment. TrAC Trends in Analytical Chemistry, 26(5), 360-374.

Danovaro, R., Bongiorni, L., Corinaldesi, C., Giovannelli, D., Damiani, E., Astolfi, P., Greci, L., \& Pusceddu, A. (2008). Sunscreens cause coral bleaching by promoting viral infections. Environmental health perspectives, 116(4), 441-447.

Tsui, M. M., Leung, H. W., Wai, T. C., Yamashita, N., Taniyasu, S., Liu, W., ... \& Murphy, M. B. (2014). Occurrence, distribution and ecological risk assessment of multiple classes of UV filters in surface waters from different countries. Water research, 67, 55-65.

Danovaro, R., \& Corinaldesi, C. (2003). Sunscreen products increase virus production through prophage induction in marine bacterioplankton. Microbial ecology, 45(2), 109-118.

Klann, A., Levy, G., Lutz, I., Müller, C., Kloas, W., \& Hildebrandt, J. P. (2005). Estrogenlike effects of ultraviolet screen 3-(4-methylbenzylidene)-camphor (Eusolex 6300) on cell proliferation and gene induction in mammalian and amphibian cells. Environmental research, 97(3), 274-281.

Schreurs, R. H., Sonneveld, E., Jansen, J. H., Seinen, W., \& van der Burg, B. (2004). Interaction of polycyclic musks and UV filters with the estrogen receptor (ER), androgen 
receptor (AR), and progesterone receptor (PR) in reporter gene bioassays. Toxicological Sciences, 83(2), 264-272.

Brausch, J. M., \& Rand, G. M. (2011). A review of personal care products in the aquatic environment: environmental concentrations and toxicity. Chemosphere, 82(11), 1518-1532.

Li, J., Ma, L. Y., \& Xu, L. (2016). Transformation of benzophenone-type UV filters by chlorine: Kinetics, products identification and toxicity assessments. Journal of hazardous materials, 311, 263-272.

Grbović, G., Malev, O., Dolenc, D., Klobučar, R. S., Cvetković, Ž., Cvetković, B., .. \& Trebše, P. (2016). Synthesis, characterisation and aquatic ecotoxicity of the UV filter hexyl 2(4-diethylamino-2-hydroxybenzoyl) benzoate (DHHB) and its chlorinated by-products. Environmental chemistry, 13(1), 119-126.

Kalister, K., Dolenc, D., Sarakha, M., Polyakova, O. V., Lebedev, A. T., \& Trebše, P. (2016). A chromatography-mass spectrometry study of aquatic chlorination of UV-filter avobenzone. Journal of analytical chemistry, 71(14), 1289-1293.

Díaz-Cruz, M. S., Llorca, M., \& Barceló, D. (2008). Organic UV filters and their photodegradates, metabolites and disinfection by-products in the aquatic environment. $\operatorname{Tr} A C$ Trends in Analytical Chemistry, 27(10), 873-887.

Santos, A. J. M., Miranda, M. S., \& da Silva, J. C. E. (2012). The degradation products of UV filters in aqueous and chlorinated aqueous solutions. Water research, 46(10), 3167-3176.

Duirk, S. E., Bridenstine, D. R., \& Leslie, D. C. (2013). Reaction of benzophenone UV filters in the presence of aqueous chlorine: kinetics and chloroform formation. Water research, 47(2), 579-587.

Sakkas, V. A., Giokas, D. L., Lambropoulou, D. A., \& Albanis, T. A. (2003). Aqueous photolysis of the sunscreen agent octyl-dimethyl-p-aminobenzoic acid: formation of disinfection byproducts in chlorinated swimming pool water. Journal of Chromatography A, 1016(2), 211-222. 
Negreira, N., Canosa, P., Rodriguez, I., Ramil, M., Rubi, E., \& Cela, R. (2008). Study of some UV filters stability in chlorinated water and identification of halogenated by-products by gas chromatography-mass spectrometry. Journal of chromatography A, 1178(1-2), 206214.

Manasfi, T., Storck, V., Ravier, S., Demelas, C., Coulomb, B., \& Boudenne, J. L. (2015). Degradation products of benzophenone-3 in chlorinated seawater swimming pools. Environmental science \& technology, 49(15), 9308-9316.

Manasfi, T., Coulomb, B., Ravier, S., \& Boudenne, J. L. (2017a). Degradation of organic UV filters in chlorinated seawater swimming pools: transformation pathways and bromoform formation. Environmental science \& technology, 51(23), 13580-13591.

Liu, Q., Chen, Z., Wei, D., \& Du, Y. (2014). Acute toxicity formation potential of benzophenone-type UV filters in chlorination disinfection process. Journal of Environmental Sciences, 26(2), 440-447.

Nakajima, M., Kawakami, T., Niino, T., Takahashi, Y., \& Onodera, S. (2009). Aquatic fate of sunscreen agents octyl-4-methoxycinnamate and octyl-4-dimethylaminobenzoate in model swimming pools and the mutagenic assays of their chlorination byproducts. Journal of Health Science, 55(3), 363-372.

Zhang, S., Wang, X., Yang, H., \& Xie, Y. F. (2016). Chlorination of oxybenzone: kinetics, transformation, disinfection byproducts formation, and genotoxicity changes. Chemosphere, 154, 521-527.

Deborde, M., \& Von Gunten, U. R. S. (2008). Reactions of chlorine with inorganic and organic compounds during water treatment—-kinetics and mechanisms: a critical review. Water research, 42(1-2), 13-51.

Richardson, S. D., Plewa, M. J., Wagner, E. D., Schoeny, R., \& DeMarini, D. M. (2007). Occurrence, genotoxicity, and carcinogenicity of regulated and emerging disinfection by- 
products in drinking water: a review and roadmap for research. Mutation Research/Reviews in Mutation Research, 636(1-3), 178-242.

Manasfi, T., De Méo, M., Di Giorgio, C., Coulomb, B., \& Boudenne, J. L. (2017b). Assessing the genotoxicity of two commonly occurring byproducts of water disinfection: chloral hydrate and bromal hydrate. Mutation Research/Genetic Toxicology and Environmental Mutagenesis, 813, 37-44.

De Méo, M., Laget, M., Di Giorgio, C., Guiraud, H., Botta, A., Castegnaro, M., \& Duménil, G. (1996). Optimization of the Salmonella/mammalian microsome assay for urine mutagenesis by experimental designs. Mutation Research/Reviews in Genetic Toxicology, 340(2-3), 51-65.

Maron, D. M., \& Ames, B. N. (1983). Revised methods for the Salmonella mutagenicity test. Mutation Research/Environmental Mutagenesis and Related Subjects, 113(3-4), 173-215.

Kim, B. S., \& Margolin, B. H. (1999). Statistical methods for the Ames Salmonella assay: a review. Mutation Research/Reviews in Mutation Research, 436(1), 113-122.

Rook, J. J. (1974). Formation of haloforms during chlorination of natural waters. Water Treat. Exam., 23, 234-243

Takanashi, H., Kishida, M., Nakajima, T., Ohki, A., Akiba, M., \& Aizawa, T. (2009). Surveying the mutagenicity of tap water to elicit the effects of purification processes on Japanese tap water. Chemosphere, 77(3), 434-439.

Richardson, S. D., DeMarini, D. M., Kogevinas, M., Fernandez, P., Marco, E., Lourencetti, C., ... \& Marcos, R. (2010). What's in the pool? A comprehensive identification of disinfection by-products and assessment of mutagenicity of chlorinated and brominated swimming pool water. Environmental health perspectives, 118(11), 1523-1530.

Manasfi, T., De Meo, M., Coulomb, B., Di Giorgio, C., \& Boudenne, J. L. (2016). Identification of disinfection by-products in freshwater and seawater swimming pools and evaluation of genotoxicity. Environment international, 88, 94-102. 
Isono, K., \& Yourno, J. (1974). Chemical carcinogens as frameshift mutagens: Salmonella DNA sequence sensitive to mutagenesis by polycyclic carcinogens. Proceedings of the National Academy of Sciences, 71(5), 1612-1617.

Trebše, P., Polyakova, O.V., Baranova, M., Kralj, M.B., Dolenc, D., Sarakha, M., Kutin, A. \& Lebedev, A.T.. (2016). Transformation of avobenzone in conditions of aquatic chlorination and UV-irradiation. Water research, 101, 95-102.

Manasfi, T., Coulomb, B., \& Boudenne, J. L. (2017). Occurrence, origin, and toxicity of disinfection byproducts in chlorinated swimming pools: An overview. International journal of hygiene and environmental health, 220(3), 591-603. 